\title{
Highly luminescent ZnCdTeS nanocrystals with wide spectral tunability for efficient color-conversion white-light-emitting-diodes
}

\author{
Ehsan Soheyli ${ }^{1}\left(\mathbb{D}\right.$, Sirous Zargoush ${ }^{2,6}$, Ahmet Faruk Yazici $^{3,6}{ }^{(\mathbb{D},}$, Reza Sahraei $^{2, *}$ (D) \\ and Evren Mutlugun ${ }^{4,5, *}$ \\ ${ }^{1}$ Department of Physics, Faculty of Science, Ilam University, Ilam 69315-516, Iran \\ 2 Department of Chemistry, Faculty of Science, Ilam University, Ilam 69315-516, Iran \\ ${ }^{3}$ Department of Material Science and Nanotechnology Engineering, Abdullah Gul University, \\ Kayseri 38080, Turkey \\ ${ }^{4}$ Department of Electrical-Electronics Engineering, Abdullah Gul University, Kayseri 38080, Turkey \\ ${ }^{5}$ UNAM-Institute of Materials Science and Nanotechnology, Bilkent University, Ankara 06800, Turkey \\ E-mail: r.sahraei@ilam.ac.ir and evren.mutlugun@agu.edu.tr
}

Received 14 June 2021, revised 14 August 2021

Accepted for publication 15 September 2021

Published 28 September 2021

\begin{abstract}
CdTe-based semiconductor nanocrystals (NCs) with size and composition-dependent efficient bandgap properties are historically mature nanomaterials for colloidal optoelectronic applications. In this work, we present the highly luminescent quaternary ZnCdTeS NCs with tunable emission across a wide visible spectrum from green to red spectral range. Prepared via a direct aqueous-based approach, a second capping agent of trisodium citrate (TSC) was used to enhance the photoluminescence (PL) emission efficiency, the chemical stability, and to spectrally widen the coverage of the emission spectra of ZnCdTeS NCs. Adding TCS created a remarkable blue shift from $572 \mathrm{~nm}$ in the absence of TSC, to $548 \mathrm{~nm}$. On the other hand, upon optimization of experimental parameters, superior ZnCdTeS NCs with a narrow PL profile typically less than $50 \mathrm{~nm}$, the high quantum efficiency of $76 \%$, and tunable emission from 515-to-645 nm were synthesized in an aqueous solvent. The keynotes were the superior and reproducible luminescent properties for the core only NCs, without shell and using relatively low reaction temperatures. It was shown that in the suggested synthesis method, the high efficiency emitted color of ZnCdTeS NCs can be easily controlled from 515-to-650 nm with excellent stability against harsh conditions. The biexponential decay profiles of samples prepared at different reaction temperatures demonstrated that the average recombination lifetime is below $40 \mathrm{~ns}$ and increases with the growth of the ZnCdTeS NCs. Results reveal that the excitonic energy levels have the main role in the recombination process. Finally, to demonstrate the functional advantages of the prepared NCs in optoelectronics, the NCs were used to fabricate color-conversion white light-emitting diodes. The color coordinate of the device is recorded as $(0.4951,0.3647)$ with CRI of 91 , CCT of $1954 \mathrm{~K}$, and LER of $251 \mathrm{~lm} \mathrm{~W} \mathrm{~W}^{-1}$ by employing only two distinct emitters for color conversion.
\end{abstract}

\footnotetext{
6 These authors contributed equally to this work.

Authors to whom any correspondence should be addressed.
} 
Supplementary material for this article is available online

Keywords: ZnCdTeS nanocrystals, high quantum efficiency, wide tunable emission, PL lifetime, white LED

(Some figures may appear in colour only in the online journal)

\section{Introduction}

CdTe-based semiconductor nanocrystals (NCs) are one of those direct-bandgap functional structures which have been and still are at the highest level of attention for both academic and industrial research [1]. They possess a great ability to be produced in the colloidal and solution-processed thinfilm forms with high photoluminescence quantum efficiency (PLQE). The emission spectrum that comes out of these NCs upon optical excitation and electrical injection can be tuned via controlling the size of NCs [2]. In this case, the role of the quantum confinement effect is much decisive to tailor the bandgap energy when the size of NCs is about the corresponding exciton radius of the bulk structure. Nonetheless, a change in the composition of such structures is another approach to modify their optical properties. In this regard, zinc ion is an excellent choice that not only increases the bandgap energy of such NCs but also can decrease the intrinsic toxicity of heavy $\mathrm{Cd}$ ions [3]. Observation of this blue shift is due to the wider bandgap energy of ZnTe bulk structure rather than that of CdTe (2.39 eV versus $1.43 \mathrm{eV}$, respectively) [4]. On the other hand, since the reactivity of $\mathrm{Zn}^{2+}$ ions with $\mathrm{Te}^{2-}$ is much slower than that of $\mathrm{Cd}^{2+}$ ions, they can act as gradient shell agents with a positive effect on both PL emissions and biocompatible characteristics.

To date, there have been some reports focusing on the optimization of routes towards ZnCdTe NCs. Adegoke and Park demonstrated that depending on the details of the synthesis of L-cysteine-capped $\mathrm{ZnCdTeS}$ quantum dots (QDs), the internal alloyed structure is a gradient or homogenous [5]. They revealed that the PLQE of the QDs with a homogenous structural nature is remarkably higher. The sulfide ions $\left(\mathrm{S}^{2-}\right)$ are another type of species that can reduce the oxidation possibility of $\mathrm{Te}^{2-}$ ions which can be included in the matrix via decomposition of thiol capping agents [6]. Therefore, using such multi-element structures can improve the functionality of CdTe NCs for optoelectronic [7], photodetector [8], chemical detection [9, 10], and biomedical screening [11] applications.

While various pieces of literature focused on the preparation of luminescent CdTe NCs in both organic and aqueous solvents $[12,13]$, there are few reports related to the $\mathrm{ZnCdTe}$ NCs particularly for direct preparation in the aqueous medium. Wang et al reported a sodium-citrate-assisted preparation of aqueous CdTe NCs and demonstrated that the ligand shell factor has a key role in the growth rate and PLQE of the obtained NCs [14]. Du et al presented a microwave-assisted method to synthesis highly luminescent ZnCdTe QDs with tunable emission from 500-to-610 $\mathrm{nm}$ as promising biological fluorescent labels [15]. They have employed glutathione as a single capping ligand to stabilize QDs to reach PLQE up to $90 \%$ but cannot be scaled up. In another study, Wang et al showed that employing such thiols also introduces the decomposed $\mathrm{S}^{2-}$ ions into the structure of NCs which occupy Te sites in the resulting alloyed structures [16]. Zhang et al prepared the 3-mercaptopropionic acid-capped ZnCdTe QDs through a colloidal reflux method. They incorporated QDs into a $\mathrm{CaCO}_{3}$ matrix to precipitate the QDs directly and enhance the emission and photostability of samples. They further presented the capability of the multi-colored ZnCdTe QDs for the fabrication of color-converted white light-emitting diodes (WLED) [7]. Almost in all of the reports related to the direct aqueous synthesis of CdTe-based NCs, thiols are the unique source of a capping agent even for solar light harvesting applications [17]. Nonetheless, trisodium citrate (TSC) is a longchain molecule widely used for the successful preparation of Ag nanoparticles [18] and I-III-VI QDs in polar solvents [19] with excellent PL emission characteristics. The co-presence of a thiol and TSC can enhance the PLQE, improve the colloidal and optical stability, and decrease the growth rate of NCs.

Although there are some reports related to $\mathrm{ZnCdTeS} \mathrm{NCs,}$ preserving the high PLQE of NCs at a wide range of visible spectrum from green to red color has not been reported in detail. In contrast to the powerful organic-phase preparation methods which are usually complicated, and expensive, with a less biofriendly feature, we present an extensive study for the synthesis of tunable $\mathrm{ZnCdTeS}$ NCs through an aqueousbased route which is a facile, simple, and effective route to prepare the alloyed $\mathrm{ZnCdTeS} \mathrm{NCs.} \mathrm{This} \mathrm{approach} \mathrm{can} \mathrm{be} \mathrm{easily}$ scaled up making it suitable for industrial applications. Special attention was paid to experimental variables with key roles in providing tunable and strong emission characteristics. For this, TSC was used to facile the widening of emitted color while preserves the high PLQE records (more than 45\%) upon engineering the synthesis conditions. The as-synthesized samples show a high record for PL emission NCs across the wide range of the visible spectrum (from 515-to-645 nm) with predominant recombination through excitonic levels. To further demonstrate the functional advantages of the present luminescent NCs, they were utilized as a color-conversion agent to fabricate efficient WLED with a CRI of 91, CCT of $1954 \mathrm{~K}$, and

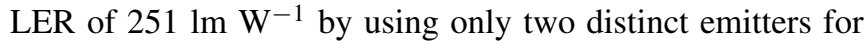
color conversion. 


\section{Materials and methods}

$\mathrm{ZnCl}_{2}, \mathrm{Cd}\left(\mathrm{CH}_{3} \mathrm{COO}\right)_{2}, \mathrm{~N}$-acetyl-L-cysteine (NAC), TSC, Te, $\mathrm{NaBH}_{4}$, acetone, ethanol, $\mathrm{NaOH}, \mathrm{H}_{2} \mathrm{O}_{2}(30 \%)$ were from Merck company and they were used as received. The Te black powder was reduced to $\mathrm{NaHTe}$ via dissolving $0.04 \mathrm{~g} \mathrm{NaBH}_{4}$ and $0.046 \mathrm{~g}$ Te in $2 \mathrm{ml}$ deionized water. The solution was subjected to a weak $\mathrm{N}_{2}$ flux for 2 min. Finally, it was stirred for $2 \mathrm{~h}$ at the ice bath until a purple solution was observed. The final product was kept at $4{ }^{\circ} \mathrm{C}$ for the preparation of $\mathrm{ZnCdTeS}$ NCs.

To prepare ZnCdTeS NCs, suitable amounts of cations were dissolved in deionized water in the presence of NAC and TSC. Typically, $0.053 \mathrm{~g} \mathrm{Cd}\left(\mathrm{CH}_{3} \mathrm{COO}\right)_{2}, 0.04 \mathrm{~g} \mathrm{ZnCl}_{2}$, $0.033 \mathrm{~g} \mathrm{NAC}$, and $0.04 \mathrm{~g}$ TSC were dissolved at the $100 \mathrm{ml}$ deionized water. The solution $\mathrm{pH}$ was kept at 8.3 by $\mathrm{NaOH}$. Then, the mixture was transferred to the 3-necked flask and stirred for $30 \mathrm{~min}$ in the $\mathrm{N}_{2}$ atmosphere. Next, $0.4 \mathrm{ml}$ of NaHTe precursor was swiftly injected into the solution (at the desired temperature). Upon injection, the reaction temperature was increased and refluxed at this temperature for a specific time. The initial molar ratio of precursors was determined as $\mathrm{Cd}: Z n: N A C: T S C: T e=1: 1.5: 0.7: 0.9: 0.36$. After $2 \mathrm{~h}$, the reaction time was terminated by turning the hitter-stirrer off and the final solution cooled down to room temperature for optical measurements. To precipitate the colloidal ZnCdTeS NCs, ethanol was slightly added to the crude solution of NCs followed by several times centrifugation (at $4000 \mathrm{rpm}$ ) and washing. Due to the significant effects of experimental conditions on the quality of prepared NCs, approximately all synthetic parameters such as injection temperature, refluxing temperature, solution $\mathrm{pH}$, the concentration of NCs, precursors' molar ratio, and reaction time were investigated.

The composition and structural properties of prepared samples were characterized by Fourier-transform infrared spectroscopy (FTIR-Vertex 70 from Bruker Co.), Energy Dispersive X-ray Spectroscopy (EDX), and EDX-mapping (Oxford INCA II energy solid-state detector), and transmission electron microscopy (TEM-FEI Talos F200S). The xray photoelectron spectrum (XPS) of the ZnCdTeS NCs was performed via Thermo Scientific K Alpha X-ray Spectrometer. The x-ray diffraction (XRD) measurement was carried out using the BRUKER AXS D8 ADVANCE MODEL. The light absorbance properties of the as-prepared samples were measured by Cary 300 Bio UV-Vis spectrophotometer (VARIAN) at the wavelength range of $300-800 \mathrm{~nm}$. The PL emission spectra of nanoparticles were recorded using a Cary Eclipse fluorescence spectrophotometer (Agilent Technology). The time-resolved PL measurements were performed by PicoQuant Fluo Time 200 time-correlated single-photon counting system equipped with a laser excitation source operating at $375 \mathrm{~nm}$ having a $5 \mathrm{MHz}$ repetition rate. Lifetimes of the samples were collected with Time Harp 260 PICO system. The decay curves were modeled and amplitude average lifetimes were calculated by fitting the data with three exponentials using FluoFit software by PicoQuant Technologies. The PLQE was calculated as reported elsewhere [19].

\section{Results and discussion}

\subsection{Structural analysis}

In general, the presence of the required amount of a suitable anion is essential to initiate a reaction in the formation of colloidal NCs, particularly in alloyed or multinary compounds. Because it has the role of feeding for cations and hence, there is a competition between the $\mathrm{Zn}^{2+}$ and $\mathrm{Cd}^{2+}$ cations to react with $\mathrm{Te}^{2-}$ anions. Therefore, to demonstrate the composition of the prepared dual-capped $\mathrm{ZnCdTeS} \mathrm{NCs}$, and also indicate the effect of NaHTe concentration (different $[\mathrm{Zn}+\mathrm{Cd}]$ :Te molar ratios) on the elemental constituent of the $\mathrm{ZnCdTeS}$ matrix, EDX analysis was performed. The $\mathrm{Zn}, \mathrm{Cd}, \mathrm{Te}$, and $\mathrm{S}$ peaks depicted in figures 1 (A) and (B) confirm the presence of the elements in the matrix of the prepared NCs. As can be seen, with increasing the $[\mathrm{Zn}+\mathrm{Cd}]$ :Te molar ratio, the amount of Te incorporated into the structure of NCs decreases, while the amount of the incorporated sulfur increases.

In most of the high-quality aqueous-soluble NCs, thiols have been utilized as a capping agent [20]. They are capable of making strong complexes with free cations at the surface of NCs and passivate them. Indeed, these stabilizing characters of such molecules are originated from their deprotonated thiolate terminals which interact with the surface of the NC matrix. NAC molecule is one of the most suitable thiols with non-toxicity and high water-solubility features that can interact via two thiol and carboxylic functional groups. It also acts as a sulfur source and introduces them to the structure of NCs. The EDX-mapping analysis of the ZnCdTeS NCs prepared at $[\mathrm{Zn}+\mathrm{Cd}]: \mathrm{NaHTe}=3.9$ further supports it (figure 1(B)). It is worthwhile mentioning that based on the quantitative data obtained from EDX measurements, with an increase in the amount of Te precursor, the relative amount of Cd-to-Zn and Te-to-S in the composition of NCs also increases.

The effective passivation of NCs by thiol-containing compounds in a direct aqueous synthesis results in better stability, improved surface properties, and high PL intensity of colloidal NCs. Considering such advantages, NAC was used in the present work. However, TSC is another well-known ligand, which is mostly used for the preparation of I-III-VI-based colloidal NCs and metallic nanoparticles. The FT-IR spectra of NAC, TSC, and final product of ZnCdTeS NCs have been shown in figure $1(\mathrm{C})$. It can be observed that NAC has four high-intensity peaks attributed to the $\mathrm{C}-\mathrm{O}\left(\sim 1290 \mathrm{~cm}^{-1}\right)$, $\mathrm{C}=\mathrm{O}\left(\sim 1590 \mathrm{~cm}^{-1}\right), \mathrm{S}-\mathrm{H}\left(\sim 2550 \mathrm{~cm}^{-1}\right)$, and N-H/O-H $\left(\sim 3400 \mathrm{~cm}^{-1}\right)$ vibrations, while TSC has four characteristic peaks at $\sim 3400,2850,1590$, and $1290 \mathrm{~cm}^{-1}$ which ascribed to $\mathrm{O}-\mathrm{H}, \mathrm{C}-\mathrm{H}, \mathrm{C}=\mathrm{O}$, and $\mathrm{C}-\mathrm{O}$ vibrations modes, respectively. Nonetheless, the $\mathrm{ZnCdTeS}$ NCs only show a broad and weak peak related to the $\mathrm{C}-\mathrm{O} / \mathrm{C}=\mathrm{O}$ vibrations. These results imply that deprotonated thiol groups highly react with the surface of NCs while the carboxylate groups partially interact with the surface of NCs.

The shape and size of the ZnCdTeS NCs were determined by TEM measurement (figure 1(D)). The direct image of the sample shows tiny NCs with relatively spherical shapes and an average size of $3.7 \mathrm{~nm}$. Since the average size of the 


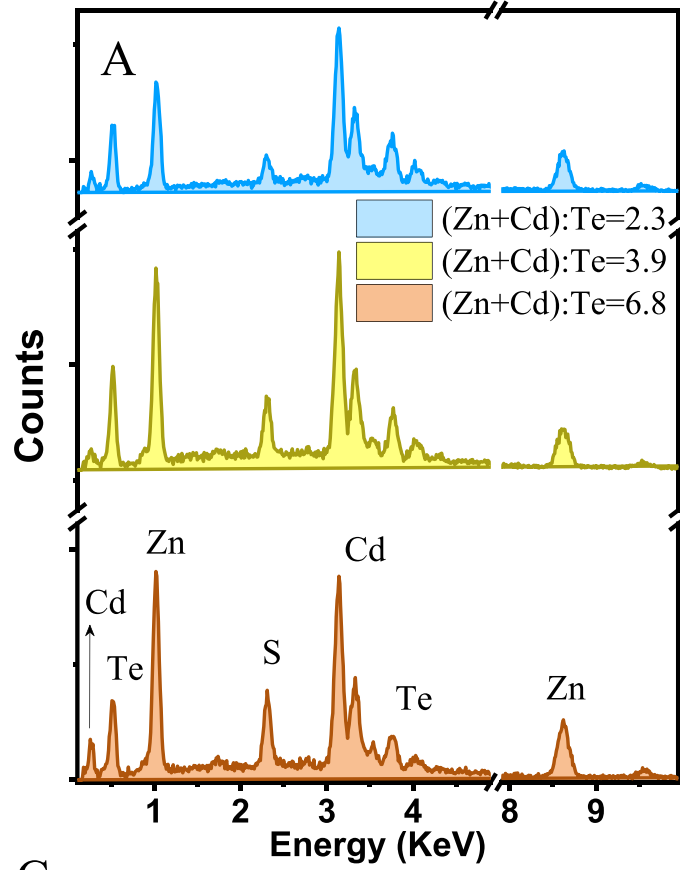

$\mathrm{C}$

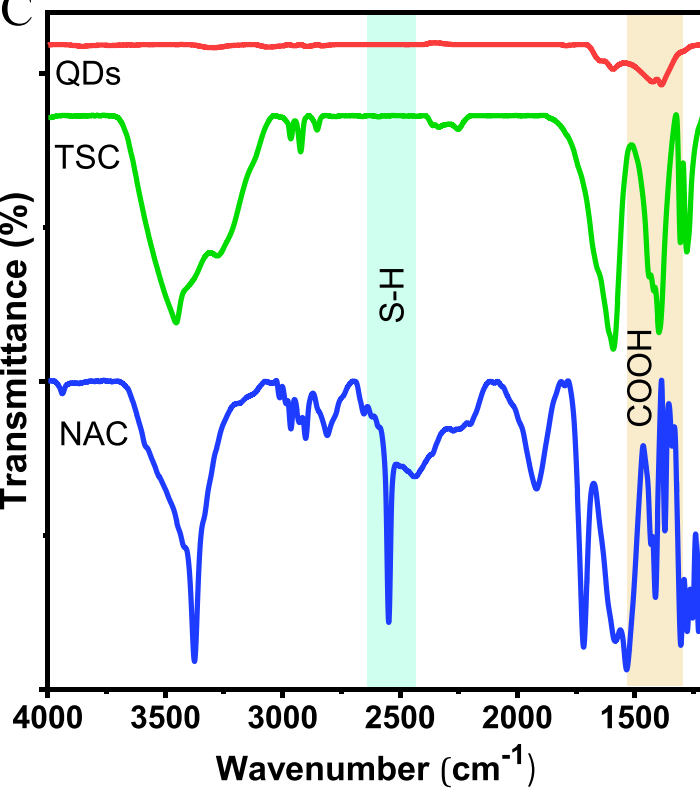

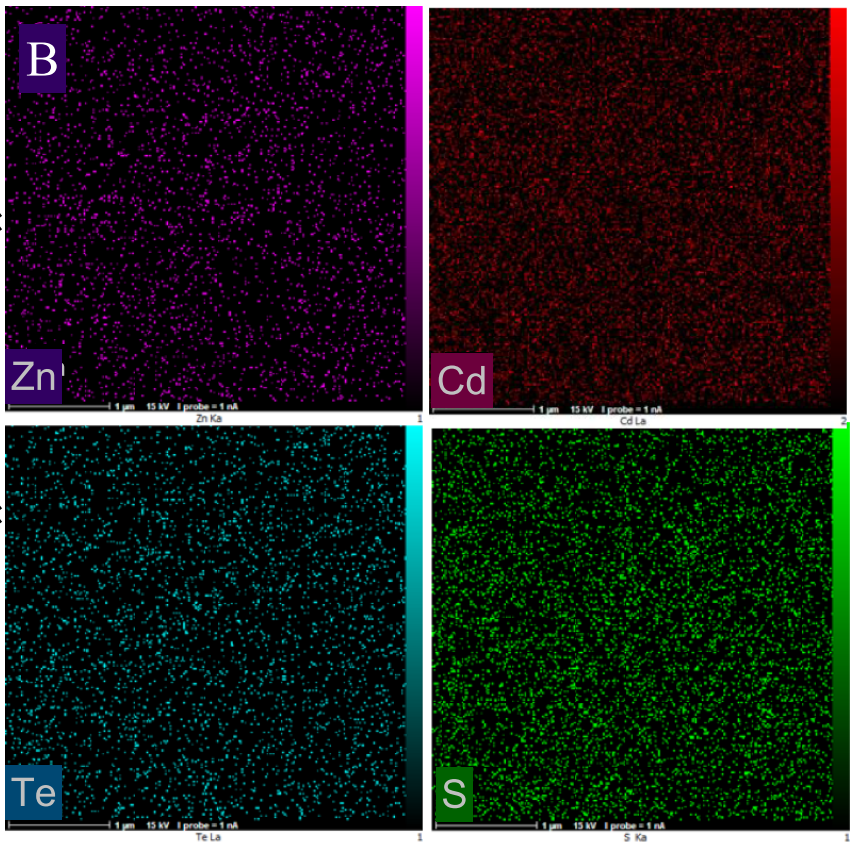

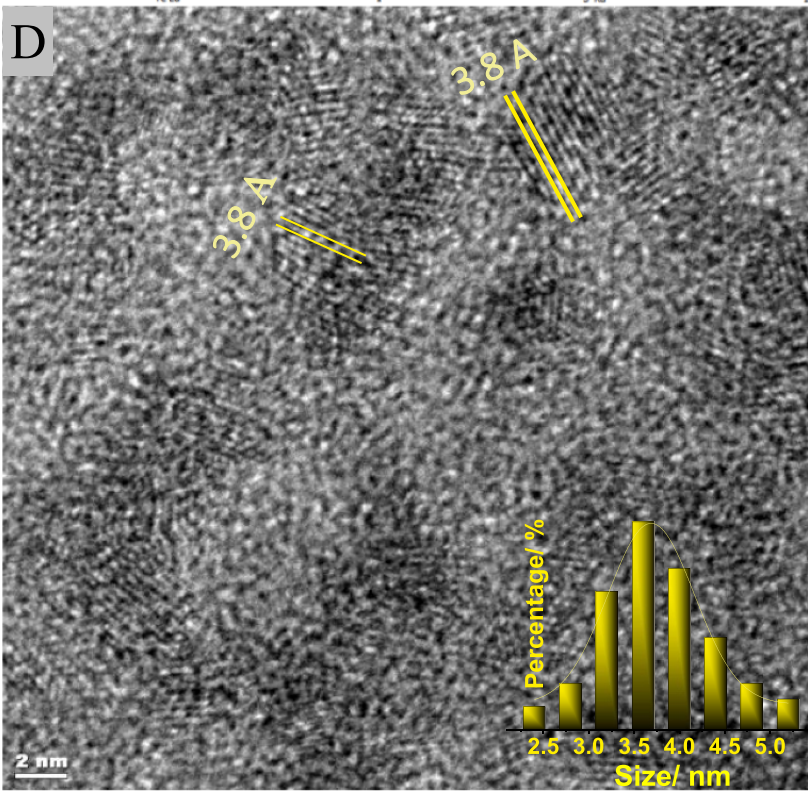

Figure 1. (A) The EDX profiles of the dual-capped ZnCdTeS NCs prepared at different $[\mathrm{Zn}+\mathrm{Cd}]: \mathrm{NaHTe}$ molar ratios. (B) The EDX-mapping result of dual-capped ZnCdTeS NCs corresponds to the [Zn+Cd]:NaHTe $=3.9$ (the scale-bars are $1 \mu \mathrm{m}$ ). (C) The FT-IR spectra of the pure NAC, TSC, and dual-capped ZnCdTeS NCs. (D) The TEM image (scale-bar of $2 \mathrm{~nm}$ ) of dual-capped ZnCdTeS NCs prepared at the reaction temperature of $100{ }^{\circ} \mathrm{C}$, injection at room temperature, and $2 \mathrm{~h}$ of reaction. Insets show the higher resolution TEM image.

prepared NCs is much lower than most of the corresponding exciton Bohr radius of bulk $\mathrm{ZnTe}, \mathrm{CdTe}, \mathrm{ZnS}$, and $\mathrm{CdS}$, which are $6.7,7.3,2.5$, and $5.8 \mathrm{~nm}$, respectively, strong quantum confinement is expected. The TEM images also revealed clear lattice fringes (showing an excellent crystallinity) with interplanar distances of about $3.8 \AA$ corresponding to the (100) Miller indices plates of the hexagonal wurtzite structure.

The EDX analysis (figures 1 (A) and (B)) revealed the type and overall amount of elements that contribute to the lattice and surface of the prepared samples. To confirm that the presented NCs are in a mixed alloyed structure without a direct clue of being in core/shell form, surface-sensitive XPS measurement was carried out for a particular sample with yellow emission (see inset of figure S1(A) (available online at stacks.iop.org/JPD/54/505110/mmedia)). The full spectrum XPS survey and its corresponding high-resolution plots are shown in figure 2. Based on the characteristic peaks, the plot approves the presence of $\mathrm{Zn}, \mathrm{Cd}, \mathrm{Te}$, and $\mathrm{S}$ as the main constituent elements of $\mathrm{NCs}$, inferring a gradient-alloyed 


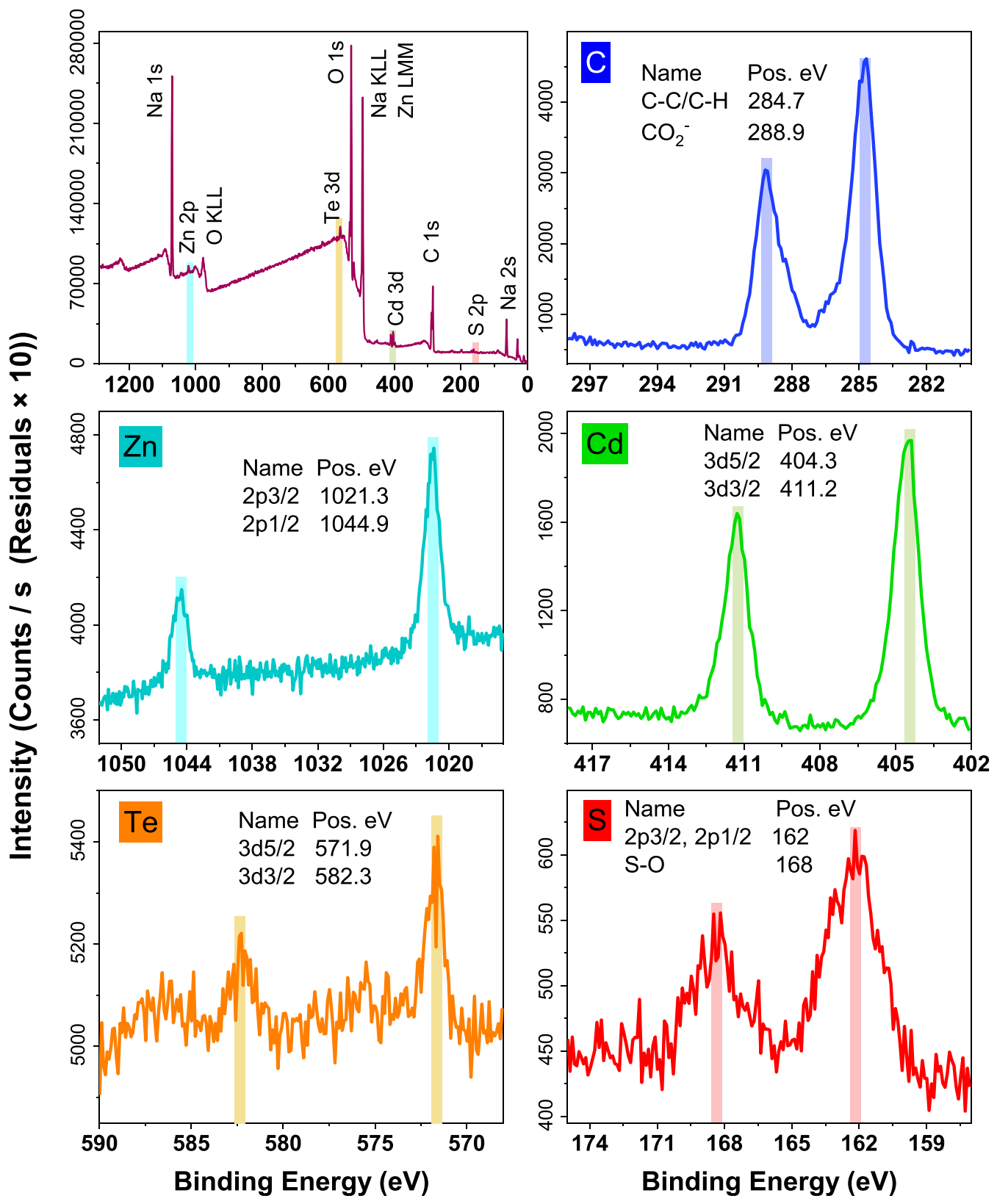

Figure 2. The XPS profile and high-resolution results for each element in the dual-capped ZnCdTeS NCs prepared at the reaction temperature of $100^{\circ} \mathrm{C}$, injection at room temperature, Cd: $\mathrm{Zn}$ molar ratio of $1: 1.5$, and $2 \mathrm{~h}$ of reaction.

structure instead of a well-resolved core/shell composition. A remarkable amount of detected carbon is attributed to the high density of surface ligands of TCS and NAC. As already mentioned, while no kind of sulfur source was used in this work, the presence of a broad peak related to the electronic states of $\mathrm{S}^{2-}$ ions in the range of $159-165 \mathrm{eV}$ showed that this ion contributes to the lattice structure of $\mathrm{ZnCdTeS} \mathrm{NCs}$ [6]. Because, if they attached just as simple surface functional groups (originating from decomposed NAC capping molecules) at the vicinity of the $\mathrm{NCs}$, the signal would be around $163-164 \mathrm{eV}$. On the other hand, it is worth mentioning that the signal located around the binding energy of $168 \mathrm{eV}$ is related to the $\mathrm{S}-\mathrm{O}$ bonds while a similar peak was not observed for $\mathrm{Te}-\mathrm{O}$ bonds. It implies the localization of sulfur ions near the surface of $\mathrm{ZnCdTeS} \mathrm{NCs} \mathrm{with} \mathrm{par-}$ tial oxidation, that might be formed during the purification process. These XPS results confirm that some sorts of gradient-alloyed $\mathrm{ZnCdTeS}$ structures have been prepared with an increase in sulfur density from the center toward the surface of the NCs, resulting in high PLQEs for the present core only ZnCdTeS NCs.

To further support the structural results, the XRD analysis of the prepared ZnCdTeS NCs was performed (figure S1). As can be observed, the obtained pattern is a multi-peak plot with very broad and low-intensity peaks. This might be due to the size-broadening effects in accordance with the quite small size of NCs obtained in the TEM image. The pattern also showed that the prepared structure is probably in the 

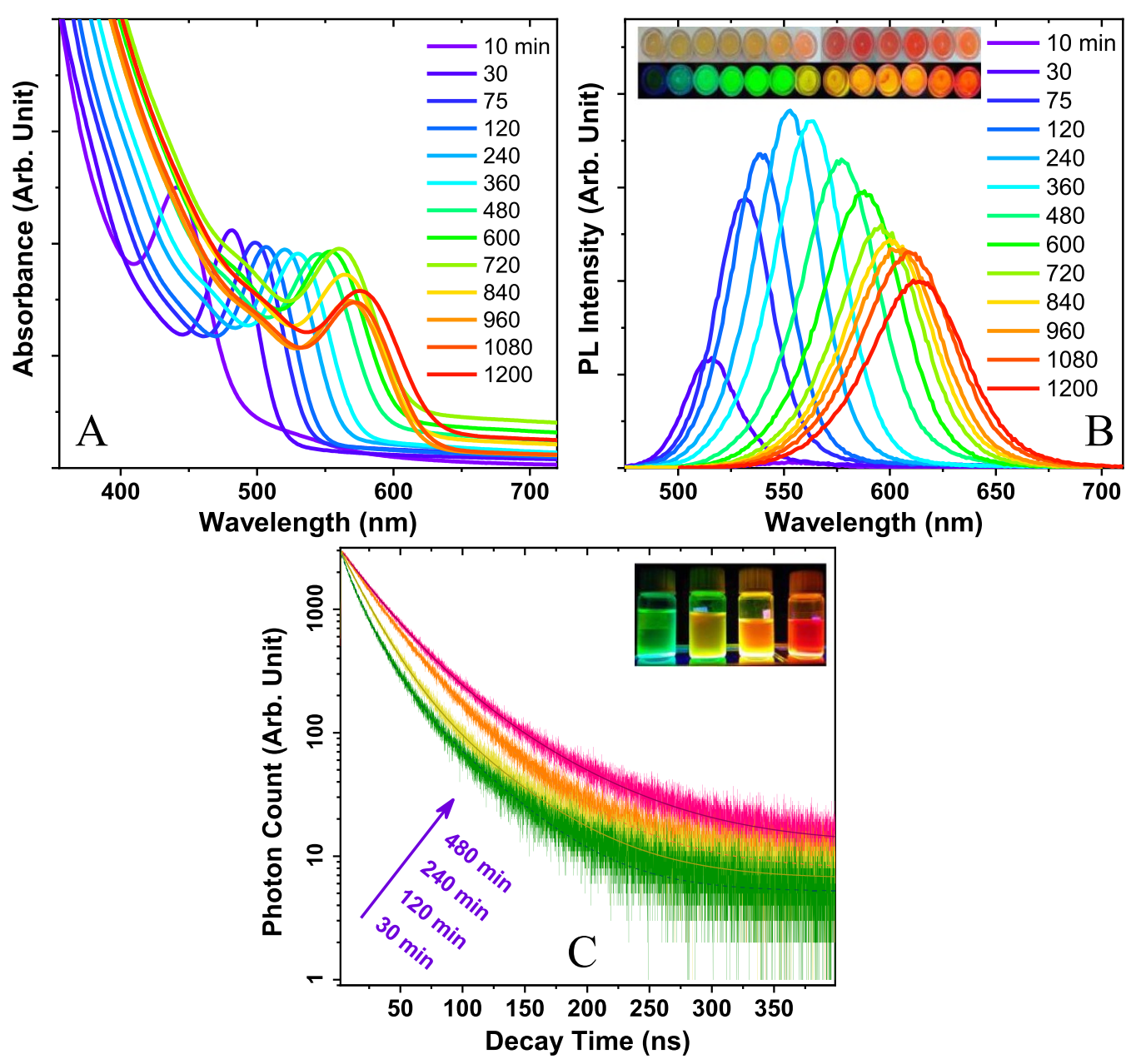

Figure 3. (A, B) Effect of reaction time on UV-Vis absorption and PL emission ( $\left.\lambda_{\text {exc }}=380 \mathrm{~nm}\right)$ spectra of colloidal ZnCdTeS NCs prepared at lower Cd precursors ( $\mathrm{ZnCd}_{\downarrow} \mathrm{TeS} \mathrm{NCs}$ ). (C) TSCPC decays of $\mathrm{ZnCd}_{\uparrow} \mathrm{TeS}$ samples with different reaction times (see figure S2(B)). Insets show photos of colloidal NCs under daylight and $365 \mathrm{~nm} / 12 \mathrm{~W}$ UV irradiation.

hexagonal wurtzite crystalline structure with non-prefer composite indicating that alloyed $\mathrm{ZnCdTeS} \mathrm{NCs}$ without a remarkable effect of resolved shell have been prepared.

\subsection{Optical analysis}

The PL excitation (PLE) and emission spectra of the asprepared colloidal ZnCdTeS NCs at different emission and excitation wavelengths have been plotted in figure S1. As can be seen, PLE spectra (dashed lines) show a relatively wide peak located around $540 \mathrm{~nm}$ for $\lambda_{\text {emis }}=600 \mathrm{~nm}$, which experiences a blue shift at longer $\lambda_{\text {emis }}$ values. With a quite small shift, the PL peak (solid lines) has been located near $547 \mathrm{~nm}$, which somehow reveals the dominance of excitonic-involved recombination processes. The best PL emission intensity was obtained for an excitation wavelength of 380 with full-width at half maximum (FWHM) of about $37 \mathrm{~nm}$. Both of these emission characteristics differ from those reported for other NC structures like I-III-VI which possess a larger shift, and a wider PL profile [21]. Finally, the relatively narrow emission profile demonstrates the purity of the emitted color, which is suitable for lighting and display applications. In this case, the as-prepared $\mathrm{ZnCdTeS}$ NCs emit an intense green color upon excitation by a set of UV lamps at $365 \mathrm{~nm} / 12 \mathrm{~W}$.

Due to the small size of as-synthesized ZnCdTeS NCs, the size-dependent optical properties are prominent in this presented work. After the injection of NaHTe at room temperature, the reaction solution was heated to $100{ }^{\circ} \mathrm{C}$ and refluxed at this temperature for different durations. To provide better emission tunability, two different amounts of $199 \mu \mathrm{mol}$ $(0.053 \mathrm{~g})$ and $274 \mu \mathrm{mol}(0.073 \mathrm{~g}) \mathrm{Cd}$ precursors were used in the initial solution. Figure 3(A) shows the UV-Vis and PL emission data recorded for as-synthesized $\mathrm{ZnCd}_{\downarrow} \mathrm{TeS}$ (small amount of $\mathrm{Cd}$ ) and $\mathrm{ZnCd}_{\uparrow} \mathrm{TeS}$ (a large amount of $\mathrm{Cd}$ ) NCs. It is clear that regardless of the amount of $\mathrm{Cd}$ used, there is a significant red-shift in both spectra with prolonging the reaction time from 30 to $1200 \mathrm{~min}$ in all spectra. The first excitonic band in the absorption spectra of $\mathrm{ZnCd}_{\downarrow} \mathrm{TeS} \mathrm{NCs}$ changes from 483 to $575 \mathrm{~nm}$, while their corresponding emission peak changes from 515 to $615 \mathrm{~nm}$ (figure 3). Similar observations were recorded for $\mathrm{ZnCd}_{\uparrow} \mathrm{TeS} \mathrm{NCs}$ where their excitonic bands' wavelength shift from 488 to 595 while their corresponding PL peak is located around 520-645 nm (figure $\mathrm{S} 2$ ). This wide red-shift in both spectra can be related to 
Table 1. The lifetime components of $\mathrm{ZnCdTeS}$ samples prepared at different reaction durations.

\begin{tabular}{lcccc}
\hline Reaction time $\rightarrow$ & $30 \min$ & $120 \min$ & $240 \min$ & 480 min \\
\hline $\mathrm{A}_{1}$ & $2174.4 \pm 49.0$ & $2422.8 \pm 41.0$ & $2381.8 \pm 35.2$ & $2204.6 \pm 34.0$ \\
$\tau_{1}(\mathrm{~ns})$ & $14.803 \pm 0.309$ & $19.584 \pm 0.293$ & $26.521 \pm 0.761$ & $28.431 \pm 0.993$ \\
$\mathrm{~A}_{2}$ & $558.4 \pm 16.1$ & $461.3 \pm 14.4$ & $562.4 \pm 15.9$ & $645.4 \pm 14.4$ \\
$\tau_{2}(\mathrm{~ns})$ & $44.565 \pm 0.846$ & $52.48 \pm 1.00$ & $56.647 \pm 0.972$ & $67.31 \pm 1.02$ \\
$\tau_{\text {avg }}(\mathrm{ns})(\mathrm{amp})$ & 20.884 & 24.85 & 32.28 & 37.24 \\
\hline
\end{tabular}

the reduction of bandgap energy due to the presence of a strong quantum confinement effect. Therefore, the bandgap engineering of these quaternary NCs can be achieved via tuning the size of the core matrix without change in composition which as reported elsewhere it makes an alloyed homogenous internal structure [5]. Moreover, significant FWHM widening from 30 to $65 \mathrm{~nm}$ for 30 and 1200 min samples, respectively, could be explained by size defocusing due to extended reaction time (figures 3(A), (B), and figure S2). The Stocks shift is another factor determining the dominance of special energy levels in absorption and recombination of carriers which was always about $30-40 \mathrm{~nm}$ for $\mathrm{ZnCd}_{\downarrow}$ TeS NCs. This parameter for $\mathrm{ZnCd}_{\uparrow} \mathrm{TeS}$ NCs changes from $30 \mathrm{~nm}$ for a shorter wavelength to $50 \mathrm{~nm}$ in a longer one. These observations somehow indicate the more effective contribution of localized midgap states in the ZnCdTeS NCs with narrower bandgap energies. Similar outcomes were concluded based on the time-resolved decay measurements, which confirmed the increasing role of midgap states with an increase in reaction time. Despite the change in the intensity of the PL emission spectra, the quality of their emitted color is preserved, demonstrating the quality of the present ZnCdTeS NCs in the colloidal phase. The calculated PLQE for $\mathrm{ZnCd}_{\downarrow} \mathrm{TeS} \mathrm{NCs}$ increased from $0.8 \%$ (in $10 \mathrm{~min}$ ) to $74 \%$ (in $240 \mathrm{~min}$ ) and then decreased to $48 \%$ after $1200 \mathrm{~min}$ of the reaction time. For $\mathrm{ZnCd}_{\uparrow} \mathrm{TeS} \mathrm{NCs}$, the best PLQE was obtained at refluxing time of 75 min with a record of $76 \%$, while the estimated emission efficiency for longer reaction times (more than $4 \mathrm{~h}$ ) was around $26 \%-63 \%$. It is worth mentioning that in both cases, NCs prepared at refluxing time of 10 min show a high Stocks shift with a very low record for PL emission intensity. It somehow reveals that it is not enough synthesis duration to prepare well-structured ZnCdTeS NCs with minimized internal and surface defects. Therefore, midgap levels are probably dominant in these cases.

To examine the PL kinetics, the time-correlated singlephoton counting (TSCPC) decays were measured. Decay profiles and detailed components of $\mathrm{ZnCdTeS}$ NCs prepared at reaction times of $30,120,240$, and $480 \mathrm{~min}$ are given in figure $3(\mathrm{C})$ and table 1 . Inset of figure $3(\mathrm{C})$ shows the digital images of the colloidal $\mathrm{ZnCd}_{\downarrow} \mathrm{TeS}$ NCs (prepared at different reaction times) under $365 \mathrm{~nm} / 12 \mathrm{~W}$ UV irradiation, which were used for TSCPC measurements and device fabrication as well. It is observed that with an increase in reaction time, the emission color changes remarkably from green to red color. As can be seen, with an increase in reaction time, the average lifetime of PL emission increases from $20.8 \mathrm{~ns}$ to $37.2 \mathrm{~ns}$. All the profiles show a biexponential feature with two components. The faster decay component $\left(\tau_{1}\right)$ which has a dominant role in recombination is attributed to the recombination of charge carriers through intrinsic excitonic states. This decay time increased from $14.8 \mathrm{~ns}$ to $28.4 \mathrm{~ns}$, upon an increase in reaction time from $30 \mathrm{~min}$ to $480 \mathrm{~min}$. On the other hand, the slow trend $\left(\tau_{2}\right)$ with a minor role in the total recombination process can be ascribed to the exciton decay via midgap surface states $[22,23]$. It showed less dependence on the reaction time and change in bandgap energy (it increases from 44.5 to $67.3 \mathrm{~ns}$ with prolonging the reaction) since the trap energy levels are localized sites within the bandgap. On the other hand, excluding the data for $30 \mathrm{~min}$ reaction, the contribution of two recombination pathways showed a different trend with an increase in reaction time. Indeed, the amplitude of the excitonic emission decreases with prolonging the reaction, while the trap emission's amplitude is enhanced. In another word, the relative amplitude of $\mathrm{A}_{2}$-to- $\mathrm{A}_{1}$ increases gradually from 3.4 to 3.8 with an increase in reaction time. It can be attributed to the more contribution of midgap trap-states (longer-lived decay component) in the recombination process with the decrease in bandgap energy. This somehow implies that because the nonradiative emissions would be also a part of $\mathrm{A}_{2}$, an increase in the $\mathrm{A}_{2}$ (with reaction time) might be due to an increase in the contribution of non-radiative centers and a subsequent decrease in PLQE.

It has been proved that experimental variables have a very important influence on the aqueous synthesis of NCs. Therefore, it is quite vital to find the optimized condition reaching the stably luminescent product. For this, optimization of reaction parameters was performed to evaluate PL emission results for $\mathrm{ZnCd}_{\downarrow} \mathrm{TeS} \mathrm{NCs}$. The first parameter was the injection temperature of NaHTe. As illustrated in the experimental section, formation of $\mathrm{ZnCdTeS} \mathrm{NCs}$ starts upon the addition of a $\mathrm{Te}^{2-}$ precursor. Figures 4(A) and (B) show the UV-Vis absorption and PL emission spectra of as-synthesized ZnCdTeS NCs at the different injection temperatures of NaHTe. All of the samples show an obvious absorption peak that shifts to the longer wavelengths (from 519 to $550 \mathrm{~nm}$ ) as the injection temperature increases from $25^{\circ} \mathrm{C}$ to $100{ }^{\circ} \mathrm{C}$. It indicates that starting the reaction at elevated temperatures is accompanied by an increase in the initial nuclei size of $\mathrm{ZnCdTeS} \mathrm{NCs}$ and the ensuing reduction in bandgap value. An increase in the injection temperature also results in an interesting red-shift of the PL emission spectrum from 546 to $580 \mathrm{~nm}$. This tunable emission from green to orange color with high intensity can be directly observed for all samples under daylight 


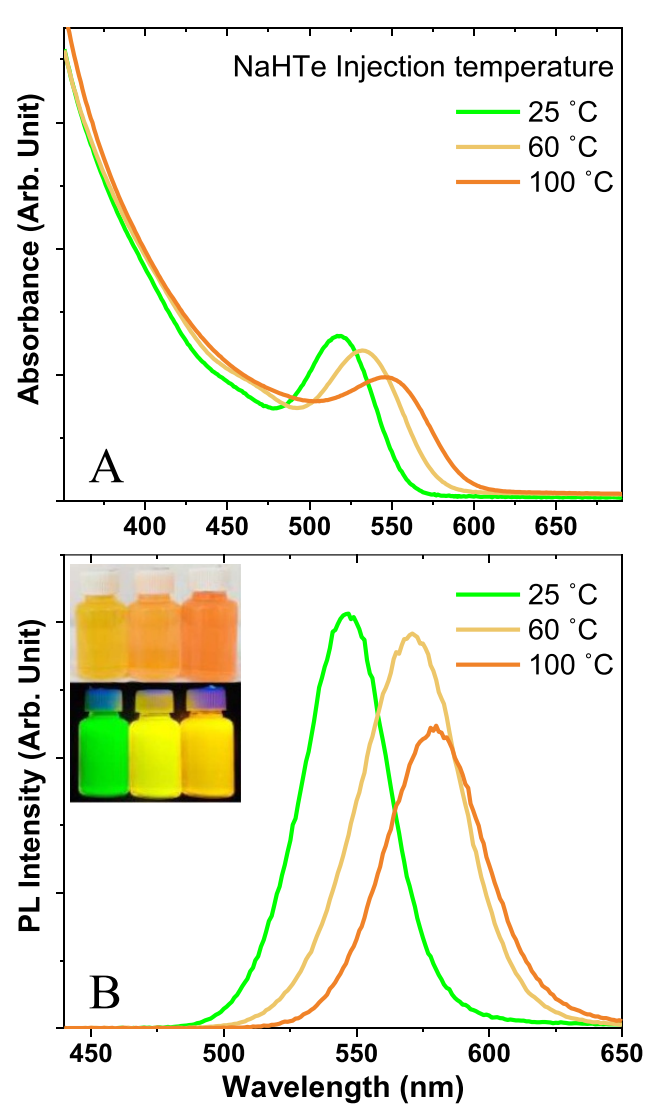

Figure 4. (A, B) UV-Vis absorption and PL emission $\left(\lambda_{\text {exc }}=380 \mathrm{~nm}\right)$ spectra of colloidal ZnCdTeS NCs prepared at different injection temperatures of NaHTe (at the solution $\mathrm{pH}$ of 8.3 and a refluxing temperature of $100{ }^{\circ} \mathrm{C}$ for $2 \mathrm{~h}$ ). Inset shows the digital images of ZnCdTeS NCs under daylight (up) and $365 \mathrm{~nm} / 12 \mathrm{~W}$ UV irradiation (down).

and $365 \mathrm{~nm}$ UV illumination at the inset of figure 4(B). The recorded Stokes shift in all cases is about $25-30 \mathrm{~nm}$, indicating the dominance of band-to-band recombination pathways. Nonetheless, the addition of Te precursor at higher temperatures results in a decrease in emission intensity as well. Furthermore, the $\mathrm{ZnCdTeS} \mathrm{NCs}$ prepared at different injection temperatures of 25,60 , and $100{ }^{\circ} \mathrm{C}$ showed high PLQE values around $74 \%, 71 \%$, and $66 \%$, respectively. Therefore, the injection of NaHTe at room temperature (which was about $25{ }^{\circ} \mathrm{C}$ ) was chosen as an optimized condition. In addition to the injection temperature, one of the most important experimental variables particularly at the colloidal synthesis of NCs is the refluxing (reaction) temperature. After the injection of $\mathrm{NaHTe}$ at $25^{\circ} \mathrm{C}$, at the present work, the reaction temperature was fixed at three different values of 25,60 , and $100{ }^{\circ} \mathrm{C}$. As can be seen in figures S3(A) and (B), a significant redshift in both absorption and emission spectra along with a remarkable enhancement in emission intensity was recorded with an increase in refluxing temperature. These observations are attributed to the two phenomena. First of all, the higher reaction temperature facilitates the growth of $\mathrm{ZnCdTeS} \mathrm{NCs}$ which leads to narrower bandgap energy and is followed by the red-shift in absorption spectra (this is a direct consequence of a strong confinement regime for the present NCs). Since the recombination process in the present work has occurred through excitonic energy levels, the emission energy also decreases (a red-shift in PL emission spectra) with a reduction of bandgap energy. Secondly, the large ZnCdTeS NCs have a small surface-to-volume ratio. This probably reduces the density of surface traps and enhances the emission intensity as well. Therefore, there is a significant enhancement in the intensity of PL emission peak which is demonstrated by irradiation of ZnCdTeS NCs with a $365 \mathrm{~nm}$ UV lamp at the inset of figure S3(B). There is a significant difference between the PLQE values of these ZnCdTeS NCs upon an increase in refluxing temperature $(0 \%, 1.9 \%$, and $74 \%)$. Therefore, a reaction temperature of $100{ }^{\circ} \mathrm{C}$ was chosen for further experiments.

Apart from the injection and the reaction temperature, we have also investigated the effect of the $\mathrm{pH}$ on the optical properties of the ZnCdTeS NCs. Liu et al showed that the solution $\mathrm{pH}$ is a very determinative factor governing the optical quality of aqueous-based preparation of NCs [24]. They showed that depends on the ligand employed for the synthesis of luminescent NCs, the suitability of the solution $\mathrm{pH}$ range is different due to the direct influence on the decomposition of the thiols to enhance surface passivation and colloidal stability. The UV-Vis absorption and PL spectra of dual-capped ZnCdTeS $\mathrm{NCs}$ at a wide range of $\mathrm{pH}$ values from 7.2 to 12.6 have been shown in figures 5(A) and (B). As can be seen, there is an obvious shift toward longer wavelengths in both spectra. This is due to the increase in the size of ZnCdTeS NCs at high pH values and subsequently a decrease in their bandgap energy [25] which again confirms the dominance of the confinement regime. The absorption peak shifts from $490-$ to- $622 \mathrm{~nm}$. Nonetheless, the most interesting part is the presence of mutual tunability and high-intensity characteristics of PL emission profiles. It is clear that with an increase in solution $\mathrm{pH}$, the PL emission peak experiences a noticeable red-shift from 524 (green) to 647 (red) $\mathrm{nm}$. Inset of figure 5(C) demonstrates that without changing the reaction temperature/time or the feeding ratio of quaternary $\mathrm{ZnCdTeS} \mathrm{NCs}$, one can reach a quite tunable emission with excellent color intensity and purity just by changing the solution $\mathrm{pH}$. Nonetheless, the best emission intensity was recorded for $\mathrm{ZnCdTeS}$ NCs prepared at $\mathrm{pH}=8.3$. It is worth noting here that while a significant shift in emission wavelength has been recorded, the asprepared NCs are still luminescent with pure emission color in the extended values of solution $\mathrm{pH}$ which is an excellent result. The estimated PLQEs for NCs prepared at $\mathrm{pH}$ values of $7.25,8.3,9,10,10.5,11.3,11.9$, and 12.6 were $40 \%, 74 \%$, $35 \%, 33 \%, 30 \%, 36 \%, 29 \%$, and $30 \%$, respectively. It should be noted that the $\mathrm{ZnCdTeS} \mathrm{NCs}$ prepared at $\mathrm{pH}=12.6$ were unstable and after 2 month storage at $4{ }^{\circ} \mathrm{C}$, its colloidal stability reduces, showing some sorts of aggregated parts in the solution. It should be noted that Matos et al prepared $\mathrm{ZnCdTe}$ NCs via both hydrothermal and microwave methods and asserted that compositional change (the real molar ratio of $\mathrm{Zn}: \mathrm{Cd}$ ) is responsible for the $\mathrm{pH}$-driven shift in absorption and emission spectra [26].

The amount of $\mathrm{Zn}$ precursor was also studied in the scope of this work (figures 6(A) and (B)). The precursors molar ratio of Cd:Zn:TSC:NAC:Te was 1:(0,1.5,3):0.7:0.9:0.36. As can 

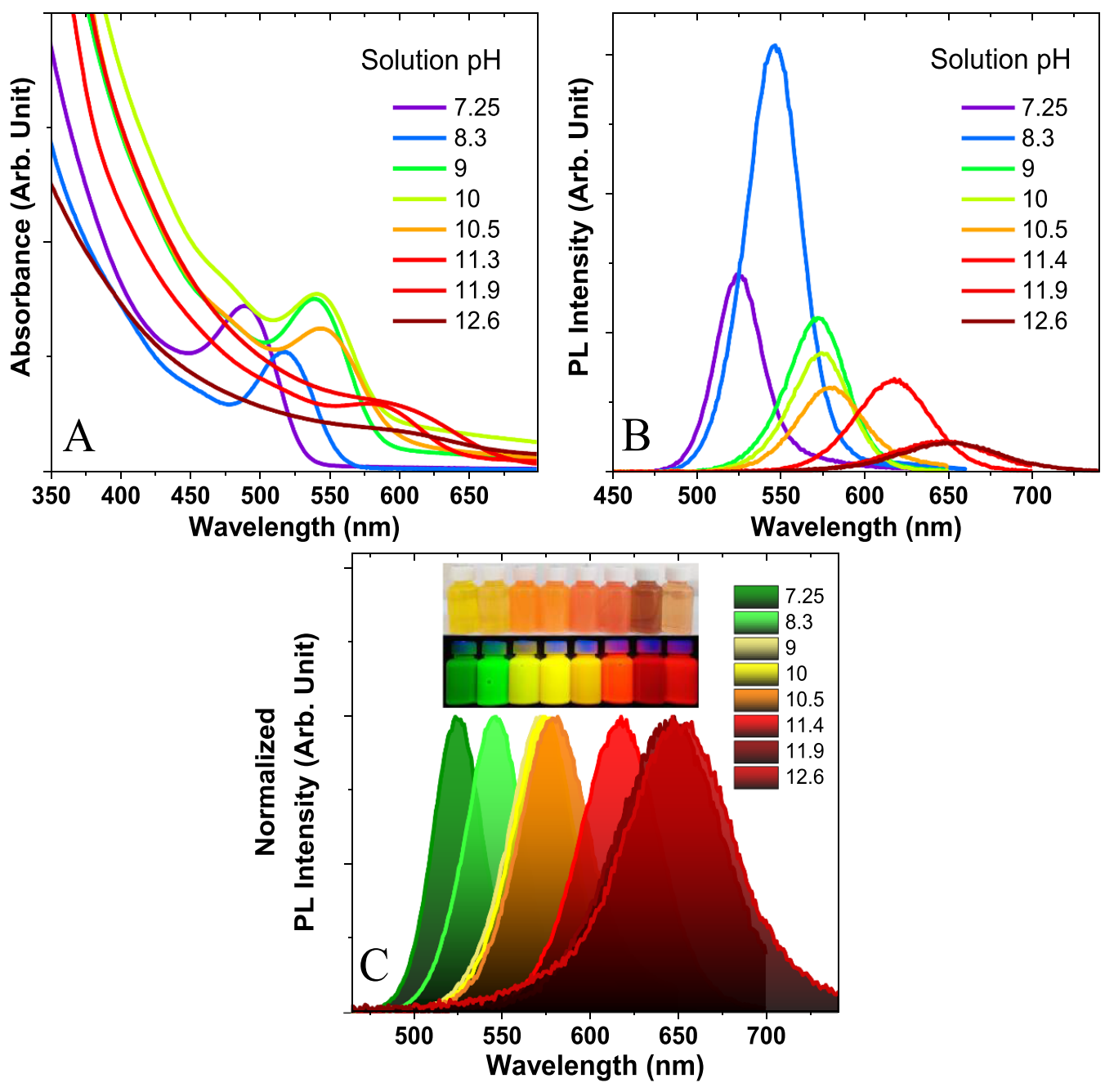

Figure 5. (A-C) UV-Vis absorption, PL emission, and normalized PL emission $\left(\lambda_{\mathrm{exc}}=380 \mathrm{~nm}\right)$ spectra of colloidal ZnCdTeS NCs prepared at different $\mathrm{pH}$ values, while other experimental parameters such as the molar ratio of precursors (Cd:Zn:NAC:TSC:

$\mathrm{Te}=1: 1.5: 0.7: 0.9: 0.36)$, refluxing temperature $\left(100^{\circ} \mathrm{C}\right)$, and reaction time $(2 \mathrm{~h})$ were constant. Inset shows the digital images of $\mathrm{ZnCdTeS}$ NCs under daylight (up) and $365 \mathrm{~nm} / 12 \mathrm{~W}$ UV irradiation (down).

be seen below, by increasing the $\mathrm{Zn}$ :Cd molar ratio from 0 to 3 , a remarkable blue shift was observed in both absorption and emission spectra. $\mathrm{Zn}^{2+}$ cations have a lower affinity to react with $\mathrm{Te}^{2-}$ anions than $\mathrm{Cd}^{2+}$ cations. Therefore, an increase in the molar ratio of $\mathrm{Zn}: \mathrm{Cd}$ from 0 to 3 , leads to a change in the effective composition of NC structure from $\mathrm{CdTeS}$ to the $\mathrm{ZnCdTeS}$ with a Cd-rich core. On the other hand, since the bandgap energy of bulk ZnTe is much higher than that of $\mathrm{CdTe}$, an increase in $\mathrm{Zn}$ content increases the bandgap energy and provides a subsequent optical shift toward shorter wavelengths. This shift in absorption spectra occurred from 551 to $495 \mathrm{~nm}$, while it changes from 580 to $524 \mathrm{~nm}$ in PL emission spectra (an intense emission with tunable characteristic is clear at the inset of figure 6(B)). The FWHM of the $\mathrm{ZnCdTeS} \mathrm{NCs} \mathrm{was} \mathrm{32,} \mathrm{40,} \mathrm{and} 45 \mathrm{~nm}$ for various $\mathrm{Cd}: \mathrm{Zn}$ molar ratios of 1:3,1:1.5, 1:0, respectively. This result, along with the obvious red-shift in both optical spectra further supports the change of bandgap energy with the Cd:Zn molar ratio. Indeed, if another reason (the overlap of bandgap and defect-related emission) is responsible for such PL broadening in longer wavelengths, one should observe a small shift in absorption and a large shift in PL spectra (upon a change in the composition of NCs) [27]. It is important to note that such size-tunable composition-dependent bandgap engineering can reveal a gradient-alloyed internal structure [5]. The PLQEs of the $\mathrm{ZnCdTeS}$ NCs prepared at the $\mathrm{Zn}: \mathrm{Cd}$ molar ratios of $0,1.5$, and 3 are $46 \%, 74 \%$, and $44 \%$, respectively.

We further investigated the concentration of the precursors considering the different amounts of $\left[\mathrm{Zn}^{2+}+\mathrm{Cd}^{2+}\right]$ where we demonstrate our results in figure $\mathrm{S} 4$. A significant absorbance of colloidal ZnCdTeS NCs prepared at the highest initial concentration of $9.8 \mathrm{mM}$ (figure $\mathrm{S} 4(\mathrm{~A})$ ) can be attributed to the formation of a large amount of $\mathrm{ZnCdTeS} \mathrm{NCs}$ in the reaction solution [28]. Besides, a decrease in the concentration of feeding precursors is accompanied by a slight red-shift in the PL emission peak from green to yellowish-green (figure S4(B)). The PLQE changed from $16 \%$ for $9.8 \mathrm{mM}$ to $74 \%$ in $4.9 \mathrm{mM}$. 

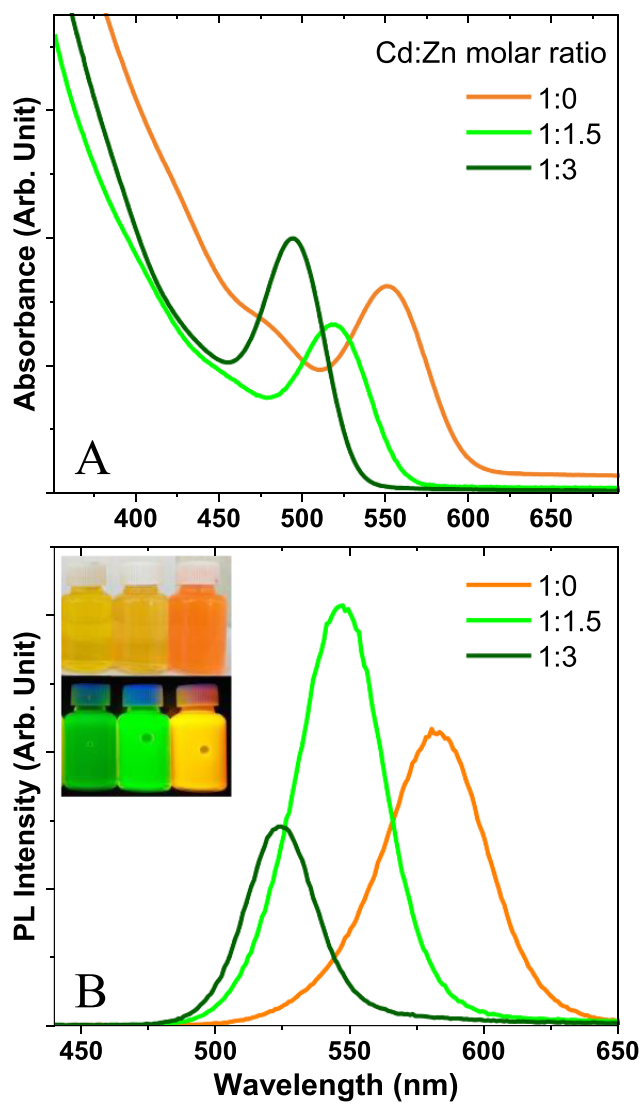

Figure 6. (A, B) UV-Vis absorption and PL emission $\left(\lambda_{\text {exc }}=380 \mathrm{~nm}\right)$ spectra of colloidal ZnCdTeS NCs prepared at different Cd:Zn molar ratios, while other experimental parameters were constant. Insets show the digital images of $\mathrm{ZnCdTeS} \mathrm{NCs}$ under daylight (up) and $365 \mathrm{~nm} / 12 \mathrm{~W}$ UV irradiation (down).

Using an appropriate amount of precursors is always a vital factor governing the quality of colloidal NCs. In this study, we optimized the amount of TSC, NAC, Zn, and Te considering the best PL emission characteristics. Figures S5(A) and (B) show the effect of TSC on the optical properties of as-prepared $\mathrm{ZnCdTeS} \mathrm{NCs.} \mathrm{It} \mathrm{was} \mathrm{found} \mathrm{that} \mathrm{the} \mathrm{presence} \mathrm{of} \mathrm{long-chain}$ TSC molecules leads to a remarkable blue shift in both UVVis absorption and PL emission spectra. This is the main merit of using this capping agent which enables us to prepare highly luminescent $\mathrm{ZnCdTe}$-based NCs in a wider region of the visible spectrum to red, through a change in various experimental parameters [26]. It changed the emission wavelength from $572 \mathrm{~nm}$ (yellow) to $548 \mathrm{~nm}$ (green) along with a three-times enhancement in PLQE from $28 \%$ in Cd:TSC $=1: 0$ to $74 \%$ in Cd:TSC $=1: 0.7$ (further explanations can be found in supplementary material). The effect of NAC was also studied in figures S5(C) and (D). Results indicated that in the absence of this capping molecule the colloidal stability of the $\mathrm{ZnCdTeS}$ NCs almost devastated and hence the PL emission completely quenches (see supplementary material). In the present study, NaHTe was used as a telluride source and it was swiftly injected into the reaction solution at room temperature. The EDX results (figure 1(A)) demonstrated that the amount of NaHTe has a keynote effect on the composition of ZnCdTeS NCs.
These results are further supported by optical data (figure S6). The obtained results showed that at the excessive amount of NaHTe the density of anions at the surface of formed NCs increases. This hinders the passivation of surface ions and the positive role of capping molecules due to the repulsive forces which result in a significant decrease in chemical stability and hence complete quenching of the PL emission spectrum (see the inset of figure S6(B)). Therefore, it was concluded that using TSC in the presence of the required amount of NAC and Te precursors is a reliable and simple approach to effectively increase the PLQE, the wavelength tunability of emitted photons, and stability of the as-prepared NCs.

To prove the suitability of the present ZnCdTeS NCs in applicable optoelectronic applications, they should have high enough stability against harsh conditions. In this regard, the chemical stability of optimized colloidal ZnCdTeS NCs (with $199 \mu \mathrm{mol} \mathrm{Cd}$ precursor) was also studied via the addition of $50 \mu \mathrm{l}$ of $30 \% \mathrm{H}_{2} \mathrm{O}_{2}$ solution into the $5 \mathrm{ml}$ of as-prepared NCs, and PL measurements were performed until the complete quenching of PL emission intensity. Figure 7(A) revealed that the emission signal decreases meaningfully after $8 \mathrm{~min}$ and it completely disappeared after $22 \mathrm{~min}$ (see the inset of figure $7(\mathrm{~A})$ ). While the time duration of stability seems not to be very long, however, one should consider the high concentration of corrosive agents added to the small volume of asprepared $\mathrm{ZnCdTeS}$ NCs. To further support it, digital images of prepared NCs storaged for 22 months at the refrigerator were added in figure 7(B), indicating the great stability of prepared NCs at all the emission wavelengths. The optical stability of the typical $\mathrm{ZnCdTeS} \mathrm{NCs}$ with green emission was also studied under irradiation of $365 \mathrm{~nm} / 6 \mathrm{~W}$ UV lamp (figure S7). Results showed that the colloidal solution containing the core only NCs are still luminescent retaining about $30 \%$ of the initial intensity.

Given the tunability of our synthesis in a wide spectral range, the suitability of our NCs in color conversion applications was investigated. NCs in the aqueous colloidal phase were mixed with $10 \%$ polyvinylpyrrolidone (avg. mol. wt. $360000)$ solution and then drop-casted on a glass petri dish. To alleviate the coffee ring effect, polymeric films were dried on a $50{ }^{\circ} \mathrm{C}$ hot plate. Free-standing color converter polymeric films placed on a commercially available inorganic GaN blue LED and the spectrum captured with Ocean Optics QEPro spectrometer. We report CRI of 91, CCT of $1954 \mathrm{~K}$, and LER of $251 \mathrm{~lm} \mathrm{~W} \mathrm{~W}^{-1}$ by using only two components for color conversion. The color coordinate is $(0.4951,0.3647)$ on CIE 1931. The samples used in this down-conversion were synthesized at different refluxing times of 30 and $480 \mathrm{~min}$ (see figure S2(B)), have PL peaks of $521 \mathrm{~nm}$ and $607 \mathrm{~nm}$. While the green and red color peak positions on the spectra of WLED given in figure $8(\mathrm{~A})$ are 551 and $632 \mathrm{~nm}$, respectively. The $30 \mathrm{~nm}$ red-shift in the spectrum of the fabricated WLED is attributed to the Stark effect. Closely packed NCs in the absence of a solvent are subjected to a stronger electric field induced by the polarization of NCs. In turn, according to the quantumconfined Stark effect, this field skews the energy well and decreases the band gap between electron and hole energy levels [29, 30]. In figure 8(B), the Persian name of Ilam (مالى) 


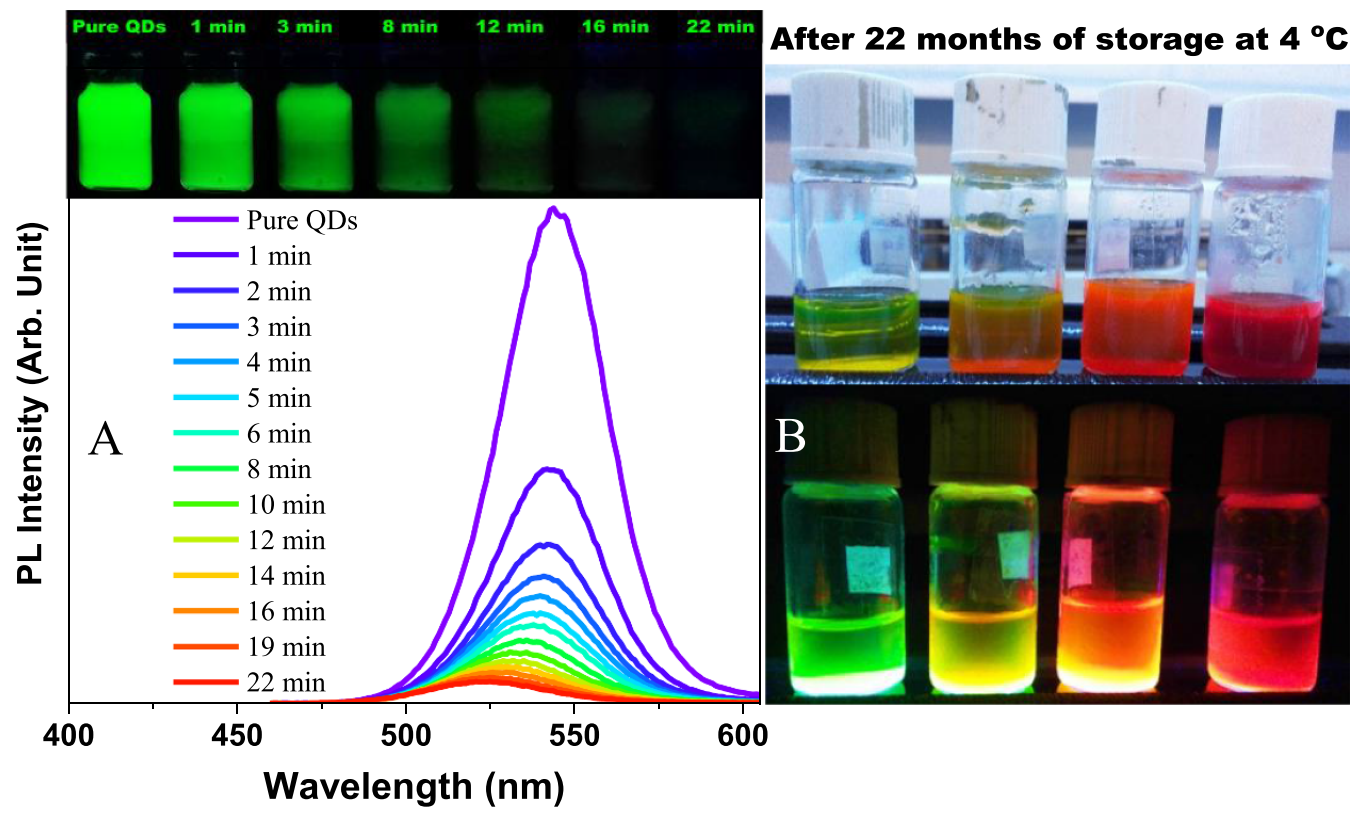

Figure 7. (A) Temporal evolution of the PL emission $\left(\lambda_{\text {exc }}=380 \mathrm{~nm}\right)$ spectrum of optimized ZnCdTeS NCs after addition of $\mathrm{H}_{2} \mathrm{O}_{2}$ solution. Inset shows the digital images of ZnCdTeS NCs under $365 \mathrm{~nm} / 12 \mathrm{~W} \mathrm{UV}$ irradiation after addition of $\mathrm{H}_{2} \mathrm{O}_{2}$. (B) Digital images of samples prepared at different reaction times, after 22 months storage at refrigerator (under daily light and UV irradiation).
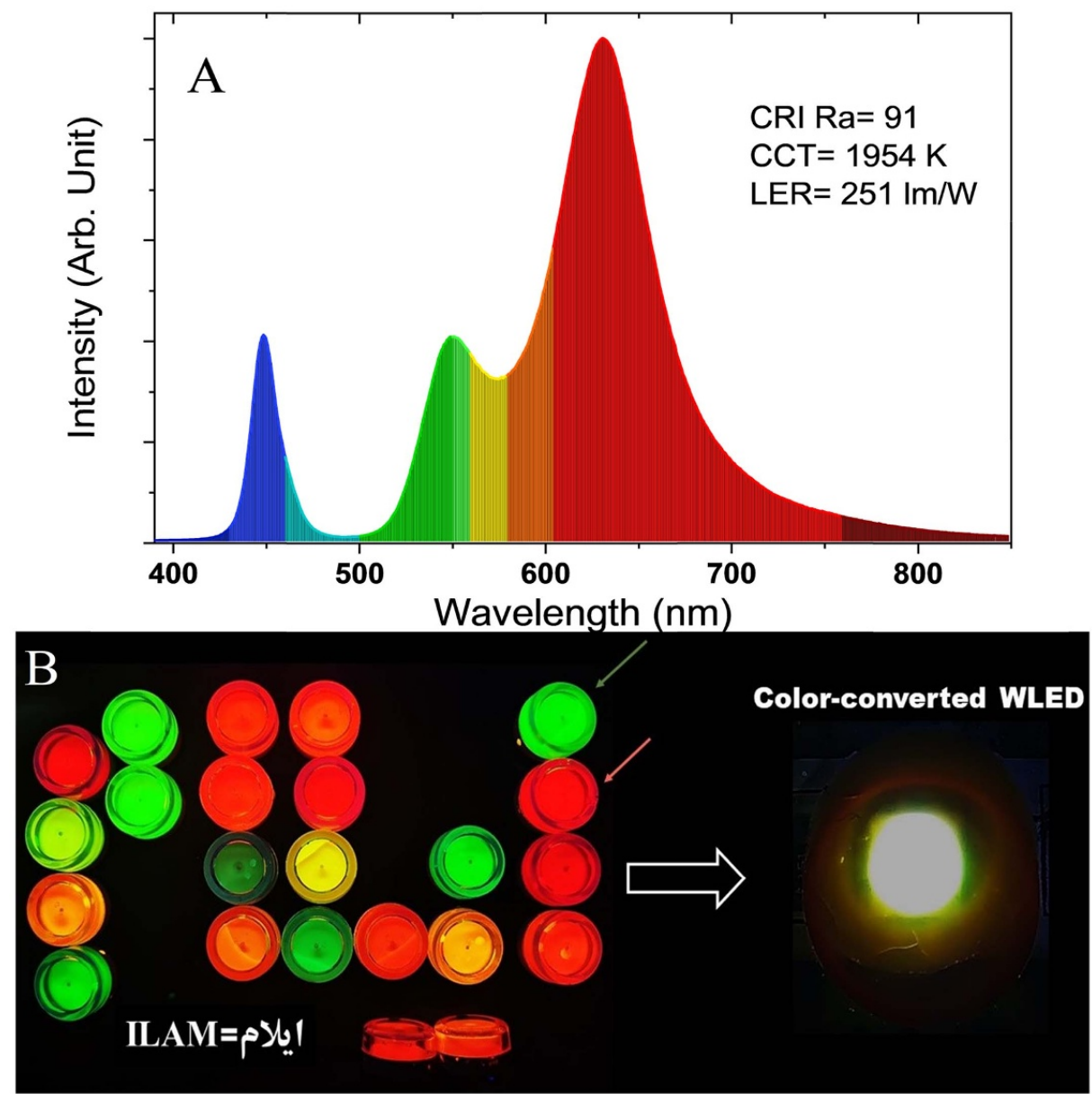

Figure 8. (A) The hybridized spectrum of blue-LED and WLED with free-standing color converter film and (B) digital images of luminescent NCs and WLED fabricated by two determined NCs of green and red emission. The Persian name of Ilam (م) ا $1=$ A city at the west of Iran) was designed via some vessels containing as-prepared NCs under irradiated by $365 \mathrm{~nm} / 6 \mathrm{~W}$ UV lamp. 
was designed via some vessels containing as-prepared NCs, and irradiated by $365 \mathrm{~nm} / 6 \mathrm{~W}$ UV lamp. A direct image of the fabricated WLED is also included, demonstrating the merits of the prepared multi-colored NCs for luminescent purposes.

\section{Conclusions}

In the present work, high-quality ZnCdTeS NCs have been prepared in the colloidal phase, with an extensive discussion on the parameters of synthesis. Through the utilization of the second ligand (TSC), the emission and colloidal stability of samples were improved, the PL emission efficiency was enhanced, and the wavelength tunability was achieved. Based on the small Stocks shift, narrow FWHM, obvious sizedependent change in both optical spectra, and data recorded for the lifetime of excited states, a remarkable contribution of excitonic states in the recombination process was confirmed. It was found that the mid-gap trap states have also a minor role in the PL emission. Driven by the quantum confinement effect of the as-prepared NCs, their emission peak position remarkably shifted while the intensities were preserved. This led to access into a wide range of emission colors from $515 \mathrm{~nm}$ in the green region to $665 \mathrm{~nm}$ in the deep red part of the visible spectrum. The calculated PLQE of samples was also a high record up to $76 \%$. The best PLQE was obtained at the optimized experimental parameters such as the injection of NaHTe at room temperature, reflux temperature of $100{ }^{\circ} \mathrm{C}$, solution $\mathrm{pH}$ of 8.3, precursors molar ratios of Cd:Zn:TSC:NAC:Te was 1:1.5:0.7:0.9:0.36, and refluxing time of $240 \mathrm{~min}$. To further support the optoelectronic merits of $\mathrm{ZnCdTeS} \mathrm{NCs,} \mathrm{a} \mathrm{color-}$ conversion WLED was fabricated by employing two distinct NCs with different emission wavelengths. The observed colorimetric parameters for the fabricated WLED were; CRI of 91, CCT of $1954 \mathrm{~K}$, and LER of $251 \mathrm{~lm} \mathrm{~W}^{-1}$, with the color coordinate of $(0.4951,0.3647)$ on CIE 1931 . The highly luminescent and tunable $\mathrm{ZnCdTeS}$ NCs synthesized with the developed robust method in the present work make these NCs excellent candidates for optoelectronic applications, which can further be improved via making a core/shell composition.

\section{Data availability statement}

The data that support the findings of this study are available upon reasonable request from the authors.

\section{Acknowledgment}

The authors would like to thank Dr Nilgün Kayacı for the XRD measurement.

\section{ORCID iDs}

Ehsan Soheyli (D) https://orcid.org/0000-0002-1403-7934 Ahmet Faruk Yazici (D) https://orcid.org/0000-0003-27477856

Reza Sahraei (D) https://orcid.org/0000-0001-7104-2126

Evren Mutlugun (D) https://orcid.org/0000-0003-3715-5594

\section{References}

[1] Jing L, Kershaw S V, Li Y, Huang X, Li Y, Rogach A L and Gao M 2016 Aqueous based semiconductor nanocrystals Chem. Rev. 116 10623-730

[2] Wang Y, Si B, Lu S, Ma X, Liu E, Fan J, Li X and Hu X 2016 Effective improvement in optical properties of colloidal CdTe@ZnS quantum dots synthesized from aqueous solution Nanotechnology 27365707

[3] Cheng J, Li D, Cheng T, Ren B, Wang G and Li J 2014 Aqueous synthesis of high-fluorescence CdZnTe alloyed quantum dots J. Alloys Compd. 589 539-44

[4] Reiss P, Protière M and Li L 2009 Core/shell semiconductor nanocrystals Small 5 154-68

[5] Adegoke O and Park E Y 2016 Size-confined fixed-composition and composition-dependent engineered band gap alloying induces different internal structures in L-cysteine-capped alloyed quaternary $\mathrm{CdZnTeS}$ quantum dots Sci. Rep. 627288

[6] Kunstman P, Coulon J, Kolmykov O, Moussa H, Balan L, Medjahdi G, Lulek J and Schneider R 2018 One step synthesis of bright luminescent core/shell CdTexS1-x/ZnS quantum dots emitting from the visible to the near infrared J. Lumin. 194 760-7

[7] Zhang Y, Chang Y, Song Z, Zhang T, Liu Q, Zhong H and Jiang Y 2017 High luminescent aqueous CdZnTe QDs incorporated in $\mathrm{CaCO} 3$ for excellent color-rendering WLEDs J. Alloys Compd. 712 543-8

[8] Zhang Z, Gu K, Yang F, Huang J, Tang K, Shen Y, Zhang J, Liao M and Wang L 2021 Enhanced UV detection performance of a CdZnTe-based photodetector through surface polishing treatments J. Mater. Chem. C 9 3601-7

[9] Mao G, Liu C, Du M, Zhang Y, Ji X and He Z 2018 One-pot synthesis of the stable CdZnTeS quantum dots for the rapid and sensitive detection of copper-activated enzyme Talanta 185 123-31

[10] Mao G, Cai Q, Wang F, Luo C, Ji X and He Z 2017 One-step synthesis of rox-DNA functionalized CdZnTeS quantum dots for the visual detection of hydrogen peroxide and blood glucose Anal. Chem. 89 11628-35

[11] Liang X-L, Bao N, Luo X and Ding S-N 2018 CdZnTeS quantum dots based electrochemiluminescent image immunoanalysis Biosens. Bioelectron. 117 145-52

[12] Xu J, Wang J, Chen Z, Xia X, Li S and Li Z 2019 Boosting photocatalytic hydrogen generation of cadmium telluride colloidal quantum dots by nickel ion doping $J$. Colloid Interface Sci. 549 63-71

[13] Algarra M, Cuevas A L, De Yuso M V M and Benavente J 2020 Insights into the formation of an emissive CdTe-quantum-dots/cellulose hybrid film J. Colloid Interface Sci. 579 714-22

[14] Wang C L, Zhang H, Xu S H, Lv N, Liu Y, Li M, Sun H Z, Zhang J H and Yang B 2009 Sodium-citrate-assisted synthesis of aqueous CdTe nanocrystals: giving new insight into the effect of ligand shell J. Phys. Chem. C 113 827-33

[15] Du J, Li X, Wang S, Wu Y, Hao X, Xu C and Zhao X 2012 Microwave-assisted synthesis of highly luminescent glutathione-capped Zn1-xCdxTe alloyed quantum dots with excellent biocompatibility J. Mater. Chem. 22 11390-5

[16] Wang Q, Fang T, Liu P, Deng B, Min X and Li X 2012 Direct synthesis of high-quality water-soluble CdTe: Zn2+ quantum dots Inorg. Chem. 51 9208-13

[17] Beydoun N, Farhat R and Halaoui L I 2020 Enhanced solar light harvesting with Q-CdTe/Se sensitized inverse opal TiO2 ACS Appl. Energy Mater. 3 3104-19

[18] Vaishnav J K and Mukherjee T K 2018 Long-range resonance coupling-induced surface energy transfer from CdTe quantum dot to plasmonic nanoparticle J. Phys. Chem. C 122 28324-36 
[19] Sabzevari Z, Sahraei R, Jawhar N N, Yazici A F, Mutlugun E and Soheyli E 2021 Long-time stable colloidal $\mathrm{Zn}-\mathrm{Ag}-\mathrm{In}-\mathrm{S}$ quantum dots with tunable midgap-involved emission J. Appl. Phys. 12963107

[20] Gaponik N and Rogach A L 2010 Thiol-capped CdTe nanocrystals: progress and perspectives of the related research fields Phys. Chem. Chem. Phys. 128685

[21] Jawhar N N, Soheyli E, Yazici A F, Mutlugun E and Sahraei R 2020 Preparation of highly emissive and reproducible $\mathrm{Cu}-\mathrm{In}-\mathrm{S} / \mathrm{ZnS}$ core/shell quantum dots with a mid-gap emission character J. Alloys Compd. 824153906

[22] Zhang X et al 2019 Synthesis and enhanced photo/thermal stability of high-luminescent red-emitting CdTe@CaCO3 composite for LED applications Ceram. Int. 45 6484-90

[23] Kalytchuk S, Zhovtiuk O, Kershaw S V, Zbořil R and Rogach A L 2016 Temperature-dependent exciton and trap-related photoluminescence of CdTe quantum dots embedded in a $\mathrm{NaCl}$ matrix: implication in thermometry Small 12 466-76

[24] Liu F-C, Cheng T-L, Shen C-C, Tseng W-L and Chiang M Y 2008 Synthesis of cysteine-capped ZnxCd1-xSe alloyed quantum dots emitting in the blue-green spectral range Langmuir 24 2162-7

[25] Soheyli E, Sahraei R and Nabiyouni G 2017 pH-dependent optical properties of $\mathrm{N}$-acetyl-L-cysteine-capped $\mathrm{ZnSe}(\mathrm{S})$ nanocrystals with intense/stable emissions $J$. Nanoparticle Res. 19 92-106

[26] Matos C R S, Candido L P M, Souza H O, Da Costa L P, Sussuchi E M and Gimenez I F 2016 Study of the aqueous synthesis, optical and electrochemical characterization of alloyed ZnxCd1-xTe nanocrystals Mater. Chem. Phys. 178 104-11

[27] Lesnyak V, Dubavik A, Plotnikov A, Gaponik N and Eychmüller A 2010 One-step aqueous synthesis of blue-emitting glutathione-capped $\mathrm{ZnSe} 1$-xTex alloyed nanocrystals Chem. Commun. 46 886-8

[28] Soheyli E, Sahraei R, Nabiyouni G, Nazari F, Tabaraki R and Ghaemi B 2018 Luminescent, low-toxic and stable gradient-alloyed Fe: $\mathrm{ZnSe}(\mathrm{S}) @ \mathrm{ZnSe}(\mathrm{S})$ core: shell quantum dots as a sensitive fluorescent sensor for lead ions Nanotechnology 29445602

[29] Walters G, Wei M, Voznyy O, Quintero-Bermudez R, Kiani A, Smilgies D-M, Munir R, Amassian A, Hoogland S and Sargent E 2018 The quantum-confined Stark effect in layered hybrid perovskites mediated by orientational polarizability of confined dipoles Nat. Commun. 94214

[30] Thuy U T D, Thuy P T, Liem N Q, Li L and Reiss P 2010 Comparative photoluminescence study of close-packed and colloidal InP/ZnS quantum dots Appl. Phys. Lett. 96073102 